\section{Ein Weihnachtsgeschenk von der Post}

Eingehend am 14. Dezember kam Post von der Post (genauer gesagt, von der Telekom, weswegen wir über die anfechtbare Postleitzahl schweigen wollen). Die Ansprache war direkt: "Sie nutzen den Datex-J-Dienst über eine Btx-Anschlußbox, die Ibnen von der Telekom vermietet und installiert wurde". Wahrscheinlich hat der Briefverfasser mit verwirrten Reaktionen auf Seiten der Empfänger gerechnet (Datex-J? Über eine BTX-Anschlußbox? Von der Telekom vermietet?) und deswegen beruhigend-vergewissernd hinzugefügt: "Ein an der Wand befestigtes granes Kästchen".

Ein Blick auf die Wand beweist es: Das graue Kästchen ist da. Also was will die Telekom? Zuerst kommt gar nicht weihnachtlich die scheinbar schlechte Nachricht: Fristgerechte Kündigung des Mietvertrages über die Btx-Anschlußbox zum Ablaufides 31. Dezember 1993. Es regt sich Groll: Fristgerecht? Eingehend am 14. Dezember zum 31. Dezember? Doch gemach, es folgt ja auch noch die gute Nachricht: "Zum gleichen Datum verzichten wir aufiunser Eigentumsrecht:für die bei Ihnen installierte Anschlußbox und bieten Ihnen diese als Schenkung an. Diese Box können Sie an dem jetzigen oder anch an einem anderen Installationsort selbstverständlich weiter auf.gewohnte Weise zur Teilnahme am Datex-J-Dienst nutzen." Der Jurist immer auf der Suche nach realen Schenkungsbeispielen in außerfamiliären Zusammenhängen ist begeistert: Voilä, das Beispiel ist da. Ob es, das wäre die glückliche Abrundung des Ganzen, etwa zusätzlich noch Rechtsprobleme aufwirft? Der geneigte Leser mag das auf Grundlage der nachfolgenden Darstellung des Gesamtsachverhalts selbst prüfen, sollte es ihm in der Muße zwischen den Jahren an EDV-rechtlichen Meditationsgegenständen fehlen.

Zuerst dämmern nicht ganz angenehme Erinnerungen aus der Studien- und Prüfungszeit herauf: Sollte es sich etwa um eine Handschenkung handeln, jenes Rechtsgebilde, das bei seinem Auftauchen in der Theorie (umgekehrt proportional zu seiner Existenz in der Praxis) eher Unruhe als Freude hervorzurufen geeignet ist? Dafür spricht die Formulierung "verzichten wir auf unser Eigentumsrecht", dagegen spricht jedoch die Wendung "bieten Ihnen diese als Schenkung an". Ein Angebot zum Abschluß eines Schenkungsvertrages also, der durch Schweigen ("Sollten Sie die Schenkung nicht annebmen wollen, teilen Sie Ibre Entscheidung Ibrem zuständigen Fernmeldeamt mit") zustandekommen kann? Doch diese Konstruktion führt in die Problemzone von $\$ 518$ Abs. 1 BGB, nach dem ein Schenkungsversprechen zu seiner Gültigkeit der notariellen Beurkundung bedarf. Zwar wird der Mangel der Form durch die Bewirkung der versprochenen Leistung geheilt ( $\$ 518 \mathrm{Abs}$. $2 \mathrm{BGB}$ ), was uns also dann möglicherweise das Eigentum an dem grauen Kästchen verschaffen würde: Nur, ist die Leistung bewirkt, wenn sie ausdrücklich nur als Angebot deklariert ist und der endgültige Zustand noch von einer Reaktion des Adressaten abhängig gemacht wird? Fragen über Fragen. Doch wenden wir uns nichtsdestotrotz der noch nicht abgeschlossenen Komplexitätsentwicklung des Rechtsgeschäfts "mit der Telekom zu, heißt es doch weiter:

"Mit der Kündigung des Mietvertrages wird nur eine Änderung im Vertragsverbältnis zwischen Ibnen und uns in der Art vollzogen, daß wir nicht mebr verpflichtet sind, Ibre Anschlußbox dauernd instandzuhalten. Den monatlichen Mietzins in Höbe von 8,05 DM (ikl. Umsatzsteuer) werden wir ab dem 1. Januar 1994 nicht mebr in Rechnung stellen. Anstelle des Mietzinses werden wir ab diesem Tag den monatlichen Preis für die Uberlassung einer Datex-J-Zugangsberechtigung in Höbe von 8,00 DM (ikl. Umsatzstener) berechnen."

Also schön und gut: 5 Pfennig sind gespart - 8,00 DM statt 8,05 DM. Aber was ist diese Erklärung juristisch? So eine Art Änderungskündigung? Das wäre zu arbeitsrechtlich gedacht. Der Zivilrechtler ist geneigt, sich stattdessen an die Novation zu erinnern (wieder mit einer studiengeprägten Mischung aus Bewunderung und Grauen): Hier wird die vertragliche Aufhebung eines Schuldverhältnisses mit der Begründung eines neuen derart verbunden, daß das neue an die Stelle des alten treten soll (animus novandi). Doch halt: Voraussetzung ist hier die vertragliche Aufhebung eines Schuldverhältnisses - wie geht das mit der Kündigung zusammen?

Wendet man dergestalt grüblerisch gestimmt die Briefseite um, so kehrt sich die Stimmung am Ende weihnachtsgemäß doch wieder ins Positive. Heißt es doch auf Seite 2:

"Sollte Ibre seit mebreren. Jahren betriebene Anschlußbox dann doch einmal gestört sein, so bieten wir Ibnen die Möglichkeit eines Austausches der Anschlußbox an."

Diese Art Ewigkeitsgarantie wünscht man sich bei Schenkungen: Sollte der verschenkte Gegenstand irgendwann einmal seinen Geist aufgeben, wird er ausgetauscht. Wie karg nimmt sich im Vergleich mit dieser Großzügigkeit der Telekom die gesetzliche Regelung zur Haftung des Schenkers aus ....

Doch die Freude währt nur kurz, denn dem Adressaten fällt leider zu spät ein, daß er ja wohl gar nicht persönlich Eigentümer des grauen Kästchens werden kann (und soll?) und demgemäß wohl nur - ja was ist? Empfangsbote? Die Rechtsfrage, an wen der Vorgang letzten Endes abzugeben ist, läßt sich einfacher entscheiden als die vorher bedachten. Eine tröstliche Botschaft?

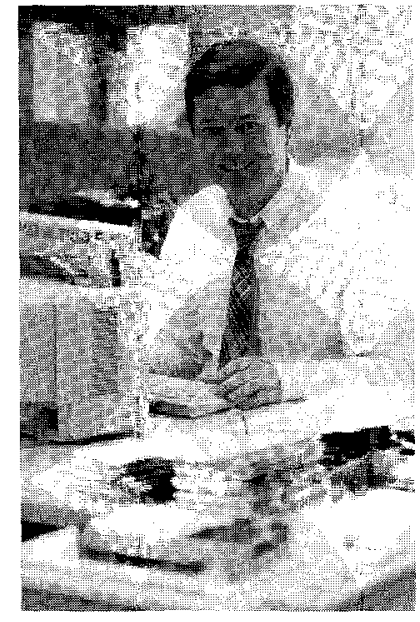

Gersweiler,

den 14. Dezember 1993

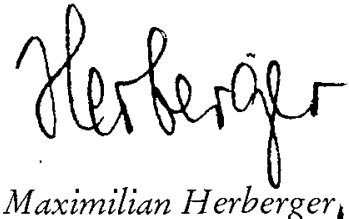

